\title{
Baseline Q waves as a prognostic modulator in patients with ST-segment elevation: insights from the PLATO trial
}

\author{
Hany Siha MD, Debraj Das BMSc, Yuling Fu MD, Yinggan Zheng MA MEd, Cynthia M. Westerhout PhD, \\ Robert F. Storey MD DM, Stefan James MD PhD, Lars Wallentin MD PhD, Paul W. Armstrong MD
}

See related commentary by Mercuri and colleagues on page 1125 and at www.cmaj.ca/lookup/doi/10.1503/cmaj.120624

\section{ABSTRACT}

Background: Baseline $\mathrm{Q}$ waves may provide additional value compared with time from the onset of symptoms in predicting outcomes for patients with ST-segment elevation. We evaluated whether baseline $Q$ waves superseded time from symptom onset as a prognostic marker of one-year mortality in patients with ST-segment elevation acute coronary syndrome. Our study was derived from data from patients undergoing primary percutaneous coronary intervention within 24 hours in the PLATelet inhibition and patient Outcomes trial

Methods: Q waves on the baseline electrocardiogram were evaluated by a blinded core laboratory. We assessed the associations between baseline $Q$ waves and time from symptom onset to percutaneous coronary intervention with peak biomarkers, ST-segment resolution on the discharge electrocardiogram, and oneyear all-cause and vascular mortality.

Results: Of 4341 patients with ST-segment elevation, $46 \%$ had baseline Q waves. Compared to those without $\mathrm{Q}$ waves, those with baseline
Q waves were older, more frequently male, had higher heart rates, more advanced Killip class and had a longer time between the onset of symptoms and percutaneous coronary intervention. They also had higher one-year all-cause mortality than patients without baseline Q waves (baseline Q waves: 4.9\%; no baseline Q waves: $2.8 \%$; hazard ratio [HR] $1.78,95 \%$ confidence interval $[\mathrm{Cl}] 1.29-2.45, p<0.001)$. Complete ST-segment resolution was greatest and all-cause mortality lowest among those with symptom onset three hours or less before percutaneous coronary intervention and no baseline $\mathrm{Q}$ waves. After multivariable adjustment, baseline $Q$ waves, but not time from symptom onset, were associated with a significant increase in all-cause mortality (adjusted HR 1.42, 95\% Cl 1.10-2.01, $p=0.046$ ) and vascular mortality (adjusted HR 1.58, 95\% Cl 1.09-2.28, $p=0.02$ ).

Interpretation: The presence of baseline Q waves provides useful additional prognostic insight into the clinical outcome of patients with ST-segment elevation. Clinical Trials.gov registration no. NCT00391872
Competing interests: See end of article for competing interests.

This article has been peer reviewed.

Correspondence to: Dr. Paul W. Armstrong, paul.armstrong@ualberta.ca

CMAJ 2012. DOI:10.1503 /cmaj.111683
$\mathrm{T}$ he clinical outcome of patients with STsegment elevation myocardial infarction (STEMI) is directly related to the extent of myocardial necrosis. ${ }^{1}$ Because the extent of necrosis is strongly influenced by the duration of symptoms, time is a key clinical proxy for the stage of evolution of STEMI. ${ }^{2}$ The length of time from the onset of symptoms is important in strategies for triage and management and for gauging prognosis. Although time from the occurrence of epicardial artery occlusion in a laboratory experimental model can be measured precisely, time from the onset of symptoms is often difficult to accurately estimate because of subjectivity and reliance on recall. Thus, establishing a more reliable method for determining the stage of myocardial infarction (MI) evolution in patients with STEMI would be useful for evaluating the potential for myocardial salvage and guiding clinical management.

There is evidence that the assessment of Q waves on the baseline electrocardiogram (ECG) in the region of ST-segment elevation may be a useful predictor of left ventricular dysfunction and outcomes in patients with STEMI given streptokinase within four to six hours of the onset of symptoms. ${ }^{3,4}$ Because prior studies of the predictive value of baseline $Q$ waves focused on patients receiving fibrinolytic therapy, we extended this question to a large population of patients with STEMI who were at high risk of adverse clinical outcomes (e.g., death, 
ardiogenic shock and heart failure) and undergoing mechanical reperfusion with percutaneous coronary intervention in the Assessment of Pexelizumab in Acute Myocardial Infarction $(\text { APEX-AMI })^{5}$ trial within six hours of symptom onset. A key finding of this study was that $\mathrm{Q}$ waves were a key prognostic factor of 90-day mortality and the composite measure of death, cardiogenic shock and heart failure; in addition, Q waves were better than time from symptom onset in predicting these 90 -day outcomes. ${ }^{6}$ Whether these findings are applicable to a more general STEMI population studied prospectively is unclear.

Given the increasing uptake of therapy for STEMI with primary percutaneous coronary intervention and the continuing challenges in achieving timely reperfusion, we sought to validate these findings in a more contemporary cohort. The PLATelet inhibition and patient Outcomes (PLATO) study not only provided this opportunity in a large population, but it also extended our evaluation to patients with less stringent ST-segment elevation entry criteria ( $1 \mathrm{~mm}$ in two contiguous leads) randomized over a wider entry window ( $24 \mathrm{~h}$ from symptom onset) and followed for a longer period ( $1 \mathrm{yr}){ }^{7} \mathrm{In}$ the current study, we aimed to prospectively evaluate whether $\mathrm{Q}$ waves in the region of qualifying ST-segment elevation on the baseline ECG provided additional value compared with time from symptom onset as a predictor of all-cause mortality in patients with ST-segment elevation undergoing primary percutaneous coronary intervention in the PLATO trial. ${ }^{7}$ We also assessed associations with vascular death, a prespecified component of the primary outcome in the PLATO trial.

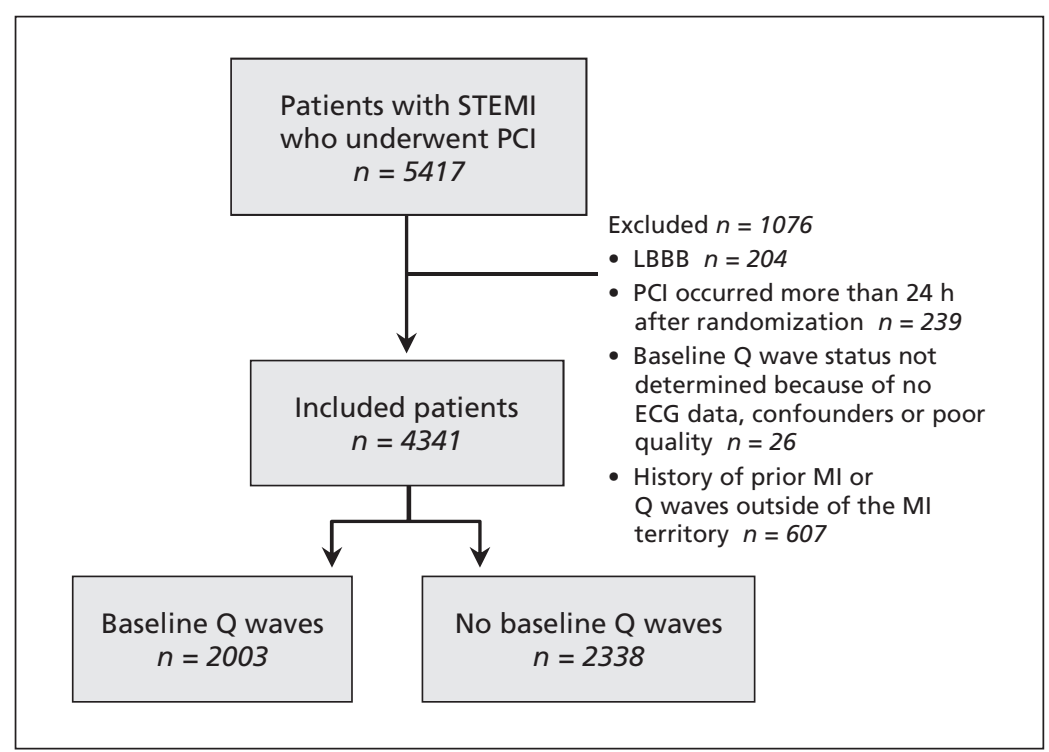

Figure 1: Selection of patients for inclusion in the study cohort. ECG = electrocardiogram, $\mathrm{LBBB}=$ left bundle branch block, $\mathrm{MI}=$ myocardial infarction, $\mathrm{PCl}=$ percutaneous coronary intervention, STEMI = ST-segment elevation myocardial infarction.

\section{Methods}

\section{Data collection}

The PLATO trial was a multicentre, randomized and double-blind study that compared the effects of the novel platelet $\mathrm{P} 2 \mathrm{Y}_{12}$ receptor inhibitor ticagrelor with traditional clopidogrel therapy. Specific details of the study design and primary results have been published. ${ }^{7.8}$ Time from the onset of symptoms to randomization in the PLATO trial was less than 24 hours, and the primary outcome was the composite outcome of death from vascular causes, MI or stroke within one year. The primary outcome of our current study was all-cause mortality within one year; vascular death was a secondary outcome.

We included patients who had at least $1 \mathrm{~mm}$ of ST-segment elevation in two contiguous leads or a left bundle branch block as identified by investigators on the qualifying ECG. Of the 5417 patients with ST-segment elevation who underwent percutaneous coronary intervention and had available baseline ECGs, we excluded 1076 patients (Figure 1). The population included in the current study was restricted to the cohort of 4341 patients who presented with ST-segment elevation acute coronary syndromes and who had undergone primary percutaneous coronary intervention within 24 hours of randomization.

\section{Electrocardiogram analysis}

The ECGs were analyzed by an ECG core laboratory (Canadian VIGOUR Centre, Edmonton, Alberta, Canada) without knowledge of the treatment assignment or outcome. The determination of the $\mathrm{Q}$ wave or $\mathrm{Q}$-wave equivalent was completed at baseline using the Selvester QRS screening criteria. ${ }^{9}$ A pathologic $\mathrm{Q}$ wave was defined as follows: $\geq 30 \mathrm{~ms}$ in lead aVF (inferior), $\geq 40 \mathrm{~ms}$ in leads I and aVL (lateral), $\geq 40 \mathrm{~ms}$ in two or more of leads V4, V5 or V6 (apical), or any Q wave $\geq 20 \mathrm{~ms}$ or QS complex in leads V2 and V3 (anterior). Q-wave equivalents were defined as follows: $\mathrm{R}$ wave $\geq 40 \mathrm{~ms}$ in $\mathrm{V} 1$ (posterior) or $\mathrm{R}$ wave $\leq 0.1 \mathrm{mV}$ and $\leq 10 \mathrm{~ms}$ in V2 (anterior). ST-segment elevation was measured at the $\mathrm{J}$ point with magnified calipers to the nearest $0.05 \mathrm{mV}$. The sum total across all leads except aVR was used to determine either STelevation sums ( $\Sigma$ ST-E) and ST-depression sums. The percent resolution of ST-elevation sums ( $\Sigma$ STE) and ST-deviation sums (elevation plus depression; $\Sigma$ ST-D) from baseline to discharge was dichotomized in accordance with guidelines by the European Society of Cardiology and the American College of Cardiology/American Heart Association as either $\geq 50 \%$ or $<50 \% .^{10}$ Inter-reader agreement for the laboratory was $96 \%$ for assessing Q waves and the ST segment. 


\section{Biomarker analysis}

Baseline troponin-I was assessed centrally using the Advia Centaur TNI-Ultra Immunoassay (Siemens, Malvern, Pennsylvania). We considered a positive result for troponin-I to be a level of $0.08 \mu \mathrm{g}$ or more per liter for the first sample taken. Locally collected biomarkers included creatine kinase-MB, troponin-T and troponin-I; these markers were reported as a ratio of the upper limit of normal. Peak biomarkers were used to assess myocardial necrosis.

\section{Statistical analysis}

We report discrete variables as percentages and continuous variables as medians and at the 25 th and 75 th percentiles. We made comparisons among patient groups using the $\chi^{2}$ and Fisher exact tests for discrete variables and the Wilcoxon rank-sum or Kruskal-Wallis tests for continuous variables. We assessed time from symptom onset to percutaneous coronary intervention as a continuous variable and as a three-level categorical variable $(\leq 3,>3$ to $\leq 6,>6 \mathrm{~h})$ as per clinical guidelines. We used restricted cubic spline functions to examine the linearity assumption graphically and statistically for the continuous variables.

We constructed Kaplan-Meier survival estimates to examine the relation between baseline Q waves and time to death within one year and between time from symptom onset to percutaneous coronary intervention and the outcome. We used Cox proportional hazards regression to adjust these relations for age, heart rate, systolic blood pressure, Killip class and index MI location (as assessed by the ECG core laboratory); these are commonly used predictors in the Global Utilization of STrategies to reduce Outcomes (GUSTO)-I mortality model. ${ }^{11}$ We report both unadjusted and adjusted hazard ratios (HR) for Q waves and time to symptom onset with 95\% confidence intervals (CIs); the adjusted associations are reported from the model in which they both appeared. We tested several interactions: Q waves and study treatment, $\mathrm{Q}$ waves and time from symptom onset, and $\mathrm{Q}$ waves and MI location. We preplanned a sensitivity analysis to include patients with prior MI or Q waves outside the MI territory. All tests used a 5\% significance level $(p<0.05)$.

\section{Results}

Of the 4341 patients included in the current analysis, 2003 patients (46\%) had pathologic $\mathrm{Q}$ waves on the baseline ECG (Figure 1). Table 1 presents the patient characteristics according to the presence of $\mathrm{Q}$ waves and time from the onset of symptoms to percutaneous coronary interven-

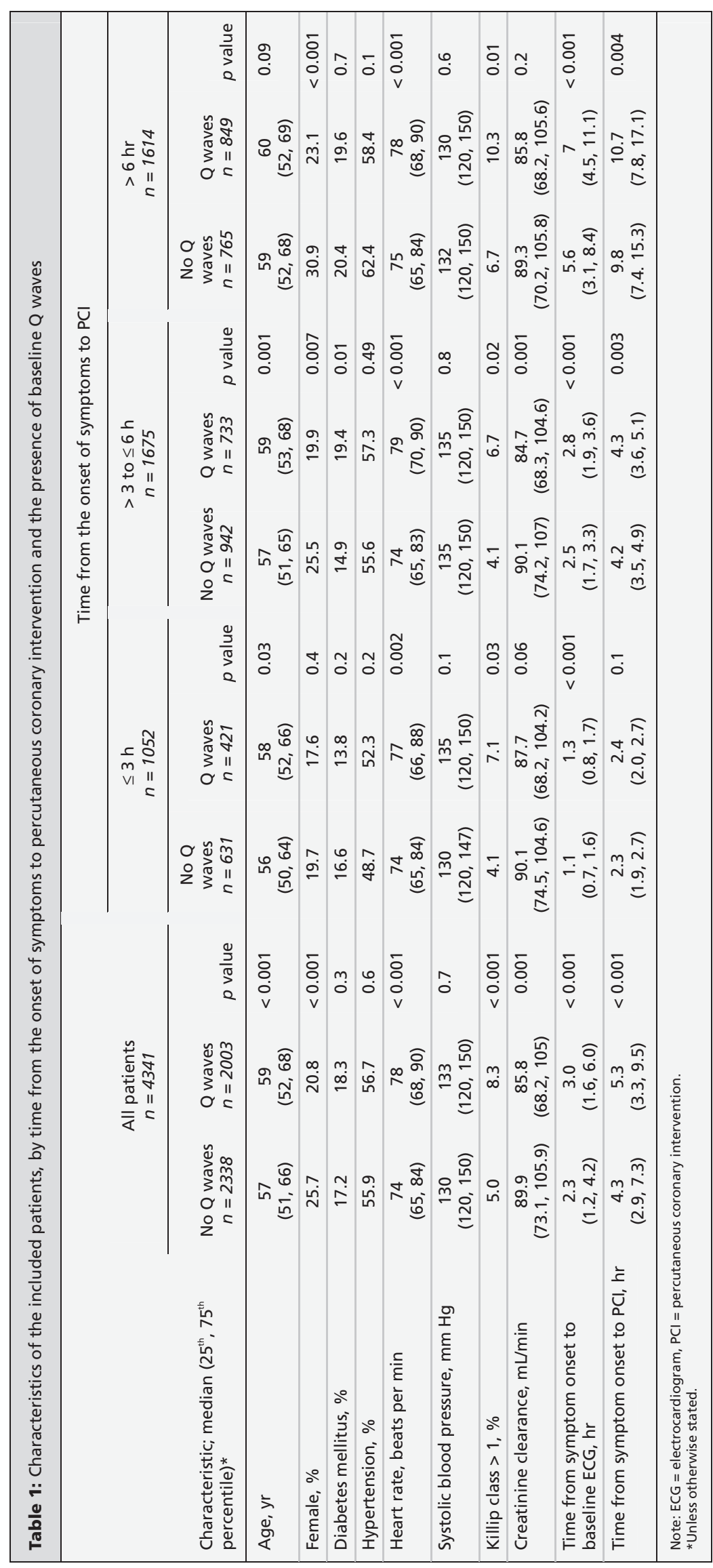




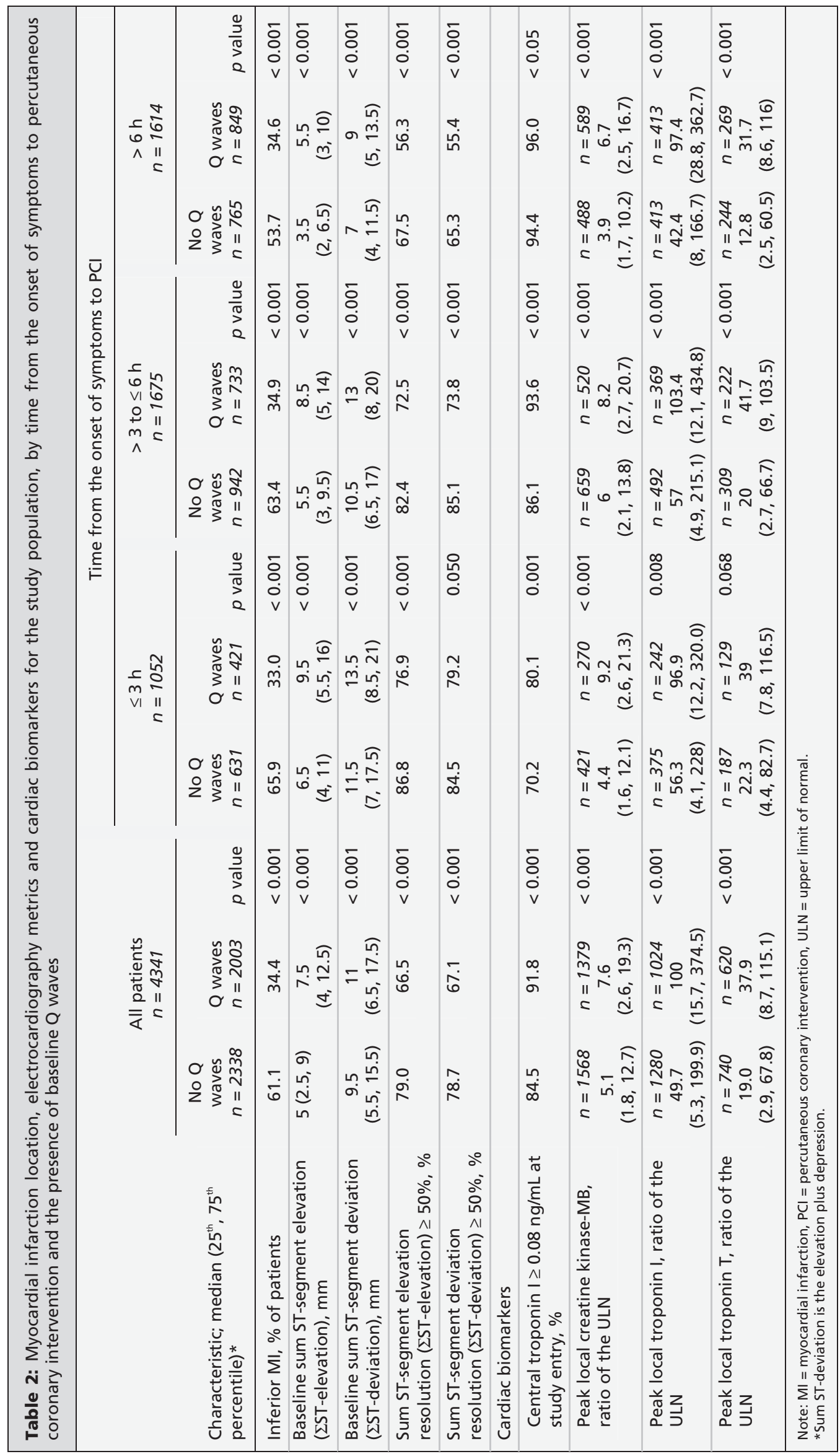


tion. Patients who presented with $\mathrm{Q}$ waves were older, more often male, had higher heart rates, more advanced Killip class and lower creatinine clearance. Time from symptom onset to baseline ECG and to percutaneous coronary intervention was longer in patients with $\mathrm{Q}$ waves $(42 \mathrm{~min})$ versus no $\mathrm{Q}$ waves $(60 \mathrm{~min})$ (both $p<0.001)$. As time from the onset of symptoms to percutaneous coronary intervention increased, the incidence of baseline Q waves increased significantly ( $\leq 3$ h: $40.0 \% ;>3$ to $\leq 6$ h: $43.8 \%$; $>6$ h: $52.6 \% ; p<0.001)$.

Patients with $\mathrm{Q}$ waves were less likely than those with no $\mathrm{Q}$ waves to have an inferior MI, greater ST-segment elevation and deviation sums at baseline, and less ST-segment resolution at discharge (Table 2, all $p<0.001$ ). Patients with $\mathrm{Q}$ waves more frequently had elevation of baseline troponin-I and had higher peak cardiac biomarkers during their hospital stay than those without $\mathrm{Q}$ waves. These findings were consistent across all three periods.

The cumulative one-year all-cause mortality was $3.8 \%$ overall and was significantly higher among patients with baseline Q waves (Figure 2; unadjusted HR 1.78, 95\% CI 1.29-2.45, $p<$ $0.001)$. The relation between $Q$ waves and death was similar irrespective of MI location $\left(p_{\text {interaction }}=\right.$ 0.9 ). When time from symptom onset to percutaneous coronary intervention was related to oneyear mortality (Figure 3), we found that patients who underwent percutaneous coronary intervention between three and six hours after the onset of symptoms tended to have worse one-year mortality than those who receive percutaneous coronary intervention in less than three hours (Figure 3; unadjusted HR 1.52, 95\% CI 0.96-2.43). Patients who underwent percutaneous coronary intervention more than six hours after the onset of symptoms had worse one-year mortality than those who underwent treatment in less than three hours (unadjusted HR 1.86, 95\% CI 1.18-2.93).

The relation between time from symptom onset to percutaneous coronary intervention and baseline Q waves for one-year all-cause mortality is shown in Appendix 1 (available at www.cmaj .ca/lookup/suppl/doi:10.1503/cmaj.111683/-/DC1). Patients with baseline Q waves consistently had poorer survival across the three periods. There was no significant interaction between $\mathrm{Q}$ waves and time from the onset of symptoms.

In a multivariable survival model for mortality that included time from symptom onset, baseline $Q$ waves were significantly associated with a $42 \%$ increase in the hazard of mortality (Figure 4). Time from the onset of symptoms, however, was no longer statistically significant. When these relations were examined for one-year vascular death (3.4\% overall), baseline $\mathrm{Q}$ waves were associated with a $58 \%$ increase, whereas time from symptom onset was no longer significant after adjustment (Figure 4). When time to

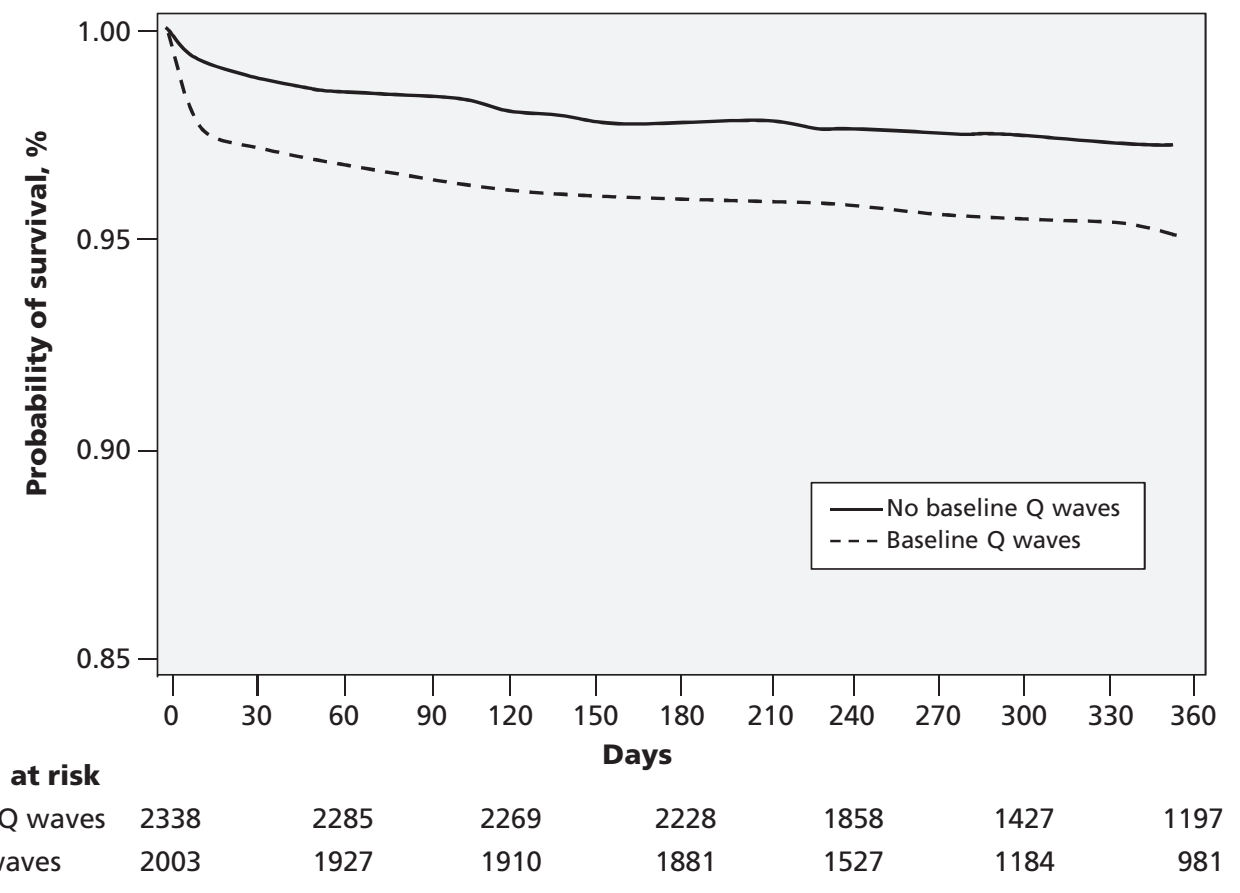

Figure 2: Kaplan-Meier survival analysis of all-cause mortality within one year of randomization, by the presence of Q waves. $p_{\text {logrank }}<0.001$. 
percutaneous coronary intervention was tested as a continuous variable, baseline $\mathrm{Q}$ waves remained statistically significant with one-year mortality (both all-cause and vascular), whereas time did not (Appendix 2, available at www.cmaj.ca /lookup/suppl/doi:10.1503/cmaj.111683/-/DC1).

When we included the 607 patients with a history of prior MI or Q waves outside of the distribution of their ST-segment elevation, the relations among baseline Q waves, time and mortality were preserved (Appendix 3, available at www.cmaj.ca /lookup/suppl/doi:10.1503/cmaj.111683/-/DC1).

\section{Interpretation}

We performed a prospective study involving a large, well-characterized population of patients with ST-segment elevation for whom percutaneous coronary intervention was intended. Our study provides new insights into the relation between time from symptom onset and the presence of baseline $\mathrm{Q}$ waves on one-year mortality in patients randomized within 24 hours of symptom onset. We found that baseline $\mathrm{Q}$ waves were superior to time from symptom onset as an independent prognostic factor for all-cause and vascular mortality in patients with ST-segment elevation. This provides robust evidence supporting the use of baseline $\mathrm{Q}$ waves as a marker of infarct evolution.
In a prior study, we found that patients with ST-segment elevation who were randomly assigned to the study treatment within a shorter period (i.e., $<6 \mathrm{~h}$ ) had higher-risk ST-segment elevation admission criteria (i.e., $\geq 2 \mathrm{~mm}$ ST-segment elevation in two anterior or lateral leads or a total of $\geq 8 \mathrm{~mm}$ ST deviation for patients with inferior MI in whom $\geq 2 \mathrm{~mm}$ ST-segment elevation in two inferior leads was required) and for whom followup was limited to 90 days. In general, the overall incidence of Q waves in the lower-risk PLATO population of $46.1 \%$ was comparable to the $55.4 \%$ seen in the APEX-AMI trial, despite the broader window of randomization.

We found that patients presenting with $\mathrm{Q}$ waves were older, more often male, had higher heart rates and higher Killip class than patients without Q waves. As well, they more often had noninferior infarcts with greater baseline ST-segment elevation and ST deviation, and they had higher baseline and peak biomarkers indicative of both earlier and greater myocardial necrosis. These patients presented later after symptom onset and had a longer time lag to percutaneous coronary intervention, and the frequency of $\mathrm{Q}$ waves rose progressively over the 24-hour period (i.e., from $40 \%$ at less than three hours to $52.6 \%$ beyond six hours).

Among the patients for whom ECG data were available at three days after admission, those with $\mathrm{Q}$ waves at baseline were less likely to achieve

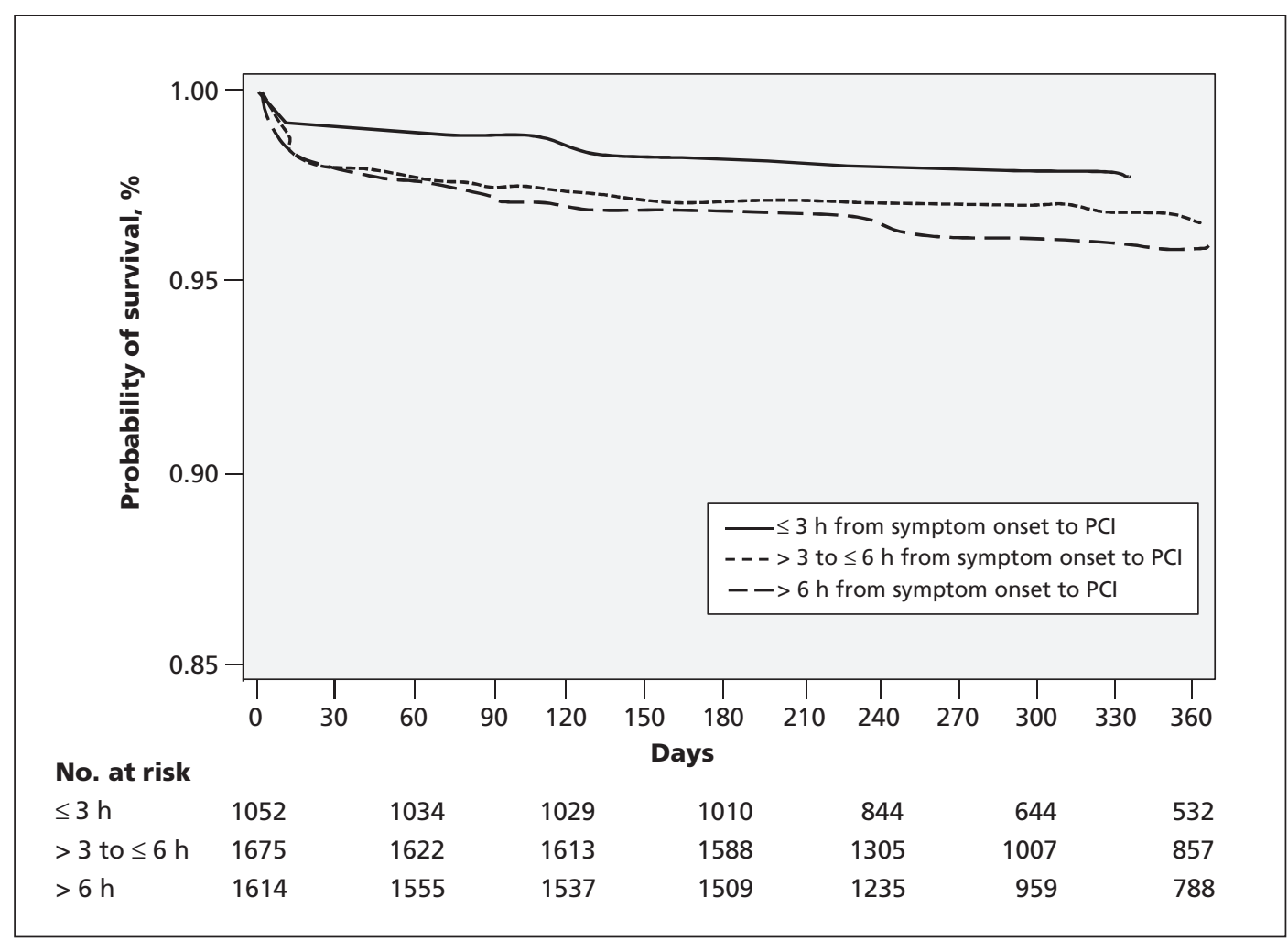

Figure 3: Kaplan-Meier survival analysis of all-cause mortality within one year, by time from the onset of symptoms to percutaneous coronary intervention (PCI). $p_{\text {logrank }}=0.03$. 
adequate ST resolution as determined by a discharge ECG. This likely relates to their longer time to reperfusion, larger subsequent infarcts and the potential role of residual-associated motion abnormalities in the left ventricular wall.

Our current study provides evidence to support greater and more systematic attention toward the presence of baseline $\mathrm{Q}$ waves on initial ECGs in patients with STEMI. This simple bedside metric provides additive value in staging the evolution of STEMI. As well, this metric should be of assistance in the selection of reperfusion strategies, triage for planned percutaneous coronary intervention and assessing prognosis. Moreover, in the not-infrequent circumstance when the time from the onset of symptoms is unclear, our findings could be especially useful. The increased role and emphasis on pre-hospital ECGs are well aligned with our evidence to support the use of a readily available baseline measure (i.e., $\mathrm{Q}$ waves) by a variety of health care providers.

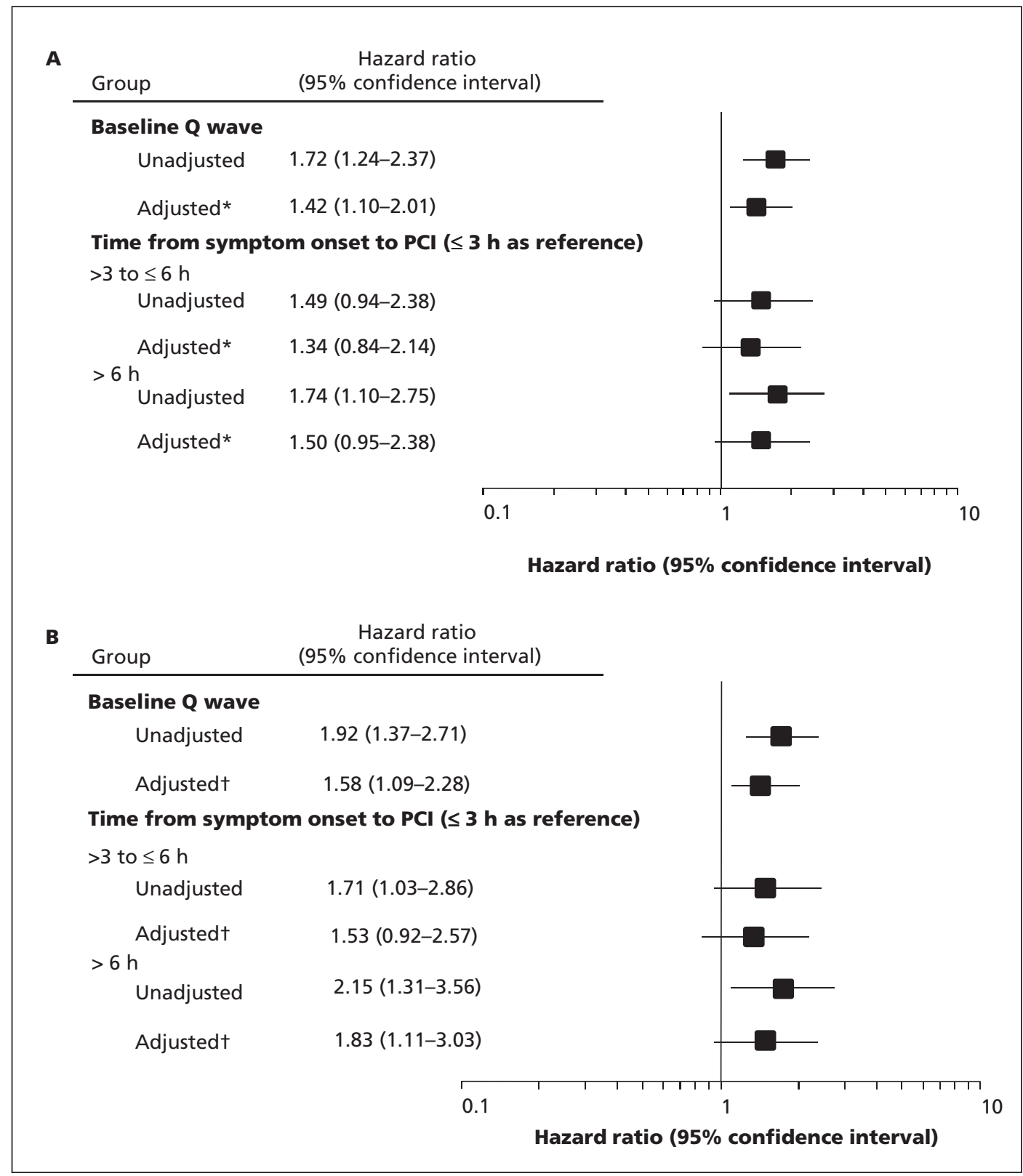

Figure 4: Associations among baseline $Q$ waves, time from symptom onset and mortality. (A) Association between all-cause mortality within one year and baseline $Q$ waves and time from symptom onset to percutaneous coronary intervention (PCI). *Adjusted for age, systolic blood pressure, heart rate, Killip class, myocardial infarction location, Q waves and time from symptom onset. (B) Association between vascular mortality within one year and baseline $Q$ waves and time from the onset of symptoms to PCl. †Adjusted for age, systolic blood pressure, heart rate, Killip class, myocardial infarction location, presence of $Q$ waves and time from symptom onset. 


\section{Limitations}

We acquired our data from a large, well-characterized population of patients with ST-segment elevation who were followed carefully for longterm mortality. Although the patients were drawn from a clinical trial, which might lead some to argue against the generalizability of our results, the liberal ECG criteria and large randomization period make our current results more clinically applicable than those from prior work. Additionally, the consistency of our findings, even after the inclusion of patients with prior MI and baseline $\mathrm{Q}$ waves outside the distribution of ST-segment elevation, is a further indication of the relevance of our results. The enhanced relations between baseline $\mathrm{Q}$ waves and the prespecified component of the primary outcome (i.e., vascular mortality) provides further support for our findings.

\section{Conclusions and implications for further research}

Baseline Q waves in patients with ST-segment elevation is a simple, readily accessible and costeffective metric that constitutes a new tool that can provide additional insight as an indicator of the evolution of infarction. Baseline Q waves are an independent prognostic factor for one-year mortality in patients with STEMI. Our study adds prospective confirmation about the prognostic value of baseline $\mathrm{Q}$ waves in broadly inclusive ST-segment elevation criteria for patients who presented within 24 hours of the onset of symptoms. This metric should prove useful in assisting therapeutic decisions about reperfusion therapy and the triage of patients with ST-segment elevation, especially when the time from the onset of symptoms is unclear.

\section{References}

1. Antman EM, Anbe DT, Armstrong PW, et al. ACC/AHA guidelines for the management of patients with ST-elevation myocardial infarction: A report of the ACC/AHA Task Force on Practice Guidelines (Writing Committee to Revise the 1999 Guidelines for the Management of Patients With Acute Myocardial Infarction). J Am Coll Cardiol 2004;44:671-719.

2. Armstrong PW, Westerhout CM, Welsh RC. Duration of symptoms is the key modulator of the choice of reperfusion for STelevation myocardial infarction. Circulation 2009;119:1293-303.

3. Andrews J, French JK, Manda SOM, et al. New Q-waves on the presenting electrocardiogram independently predict increased cardiac mortality following a first ST-elevation myocardial infarction. Eur Heart J 2000;21:647-53.

4. Wong CK, Gao W, Raffel OC, et al. Initial Q-waves accompanying ST-segment elevation at presentation of acute myocardial infarction and 30-day mortality in patients given streptokinase therapy: an analysis from HERO-2. Lancet 2006;367:2061-7.

5. APEX-AMI Investigators, Armstrong PW, Granger CB, et al. Pexelizumab for acute ST-elevation myocardial infarction in patients undergoing primary percutaneous coronary intervention: a randomized controlled trial. JAMA 2007;297:43-51.

6. Armstrong PW, Fu Y, Westerhout CM, et al. Baseline Q-wave surpasses time from symptom onset as a prognostic marker in ST-segment elevation myocardial infarction patients treated with primary percutaneous coronary intervention. J Am Coll Cardiol 2009;53:1503-9.

7. Wallentin L, Becker RC, Budaj A, et al. Ticagrelor versus clopidogrel in patients with acute coronary syndromes. $N$ Engl J Med 2009;361:1045-57.

8. James S, Akerblom A, Cannon CP, et al Comparison of ticagrelor, the first reversible oral $\mathrm{P} 2 \mathrm{Y} 12$ receptor antagonist, with clopidogrel in patients with acute coronary syndromes: Rationale, design, and baseline characteristics of the PLATelet inhibition and patient Outcomes (PLATO) trial. Am Heart J 2009;157: 599-605.

9. Anderson WD, Wagner NB, Lee KL, et al. Evaluation of a QRS scoring system for estimating myocardial size. VI: identification of screening criteria for non-acute myocardial infarcts. Am J Cardiol 1988;61:729-33.

10. Schröder R, Wegscheider K, Schröder K, et al. Extent of early ST segment elevation resolution: a strong predictor of outcome in patients with acute myocardial infarction and a sensitive measure to compare thrombolytic regimens. A substudy of the International Joint Efficacy Comparison of Thrombolytics (INJECT) trial. J Am Coll Cardiol 1995;26:1657-64.

11. Lee KL, Woodlief LH, Topol EJ, et al. Predictors of 30-day mortality in the era of reperfusion for acute myocardial infarction. Circulation 1995;91:1659-68.

Affiliations: From the University of Alberta (Siha, Das, Fu, Zheng, Westerhout, Armstrong), Edmonton, Alta.; the University of Sheffield (Storey), Sheffield, United Kingdom; and the Uppsala Clinical Research Center (James, Wallentin), Uppsala, Sweden

Competing interests: Robert Storey has received research grants from AstraZeneca, Accu-Metrics, Eli Lilly, Daiichi Sankyo and Merck. He has received consultancy fees from these companies as well as from Novartis, Eisai, BristolMyers Squibb, The Medicines Company, Iroko Pharmaceuticals and Medscape. He has received payment for manuscript preparation from AstraZeneca.

Stefan James has received grants from AstraZeneca, Eli Lilly, Bristol-Myers Squibb, Terumo, Medtronic, and Vascular Solutions. He has received consultancy fees from AstraZeneca, Eli Lilly and Medtronic, and travel support from AstraZeneca and Bristol-Myers Squibb. He has received fees for participating in review activities from AstraZeneca and Merck. He has received payment for lectures from AstraZeneca and Eli Lilly.

Lars Wallentin has received research grants, honoraria, lecture fees, consultancy fees and travel support from AstraZeneca. He has received grants and lecture fees from Merck/Schering Plough, Boehringer Ingelheim, BristolMyers Squibb and GlaxoSmithKline. He has received consultancy fees from these companies, as well as from Pfizer, Regado Biosciences, Portola, CSL Behring and Athera Biotechnologies.

Paul Armstrong has received research grants from Boehringer Ingelheim, Leuven Coordinating Centre, sanofiaventis Canada, Eli Lilly, Merck, Duke Clinical Research Institute, Scios Inc., Ortho Biotech, Johnson \& Johnson, Janssen Ortho, GlaxoSmithKline, Uppsala Clinical Research Center, AstraZeneca, and Regado Biosciences. He has received consultancy fees from sanofi-aventis, Merck, Regado Biosciences, F. Hoffman La Roche Ltd, GlaxoSmithKline and Takeda Pharmaceuticals. No competing interests declared by Cynthia Westerhout, Yinggan Zheng, Yuling Fu, Debraj Das and Hany Siha.

Contributors: All of the authors were involved in the study concept and design. Yinggan Zheng and Cynthia Westerhout were responsible for the statistical analysis, and all authors were responsible for the interpretation of the data. Hany Siha and Paul Armstrong were responsible for drafting the manuscript. All authors revised the manuscript critically for important intellectual content and approved the final version submitted for publication.

Funding: The PLATO trial was supported by AstraZeneca. 